\title{
Early computed tomographic control
}

\author{
R. Scott Mitchell, MD
}

See related brief communication online, page e25.
From the Falk Cardiovascular Research Center, Stanford University Medical Center, Stanford, Calif.

Received for publication July 25, 2006; accepted for publication Aug 8, 2006.

Address for reprints: R. Scott Mitchell, MD, Falk Cardiovascular Research Center, Stanford University Medical Center, Stanford, CA 94305-5407 (E-mail: rsmitch@ stanford.edu)

J Thorac Cardiovasc Surg 2006;132:1257

0022-5223/\$32.00

Copyright $\odot 2006$ by The American Association for Thoracic Surgery

doi:10.1016/j.jtcvs.2006.08.039
$\mathrm{T}$ The brief communication by Dr Bauernschmitt and colleagues ${ }^{1}$ printed online in this issue of the Journal presents a very interesting case report. Carotid thrombosis is clearly a severe and potentially catastrophic complication. Fortunately, early discovery permitted definitive treatment before further complications ensued. Undoubtedly, this thrombotic event was precipitated either by a perturbation of flow caused by overstenting of the carotid orifice or by an injury to the adjacent aorta or proximal carotid artery. Unfortunately, several critical and pertinent details are omitted. First, was the carotid orifice overstented, and if so, by how much? Second, what was the configuration of the proximal end of the stent graft, the "free flow" or the "closed web" design? Third, were there balloon inflations that extended proximal to the fabric of the stent graft? Finally, what was the length of the proximal landing zone measured from the distal portion of the carotid orifice to the proximal extent of the aneurysm along both the greater and lesser curves? Figure 1, A, would suggest that this distance was quite short, mandating very proximal placement to avoid a type $1 \mathrm{~A}$ endoleak.

Although answers to these technical details might shed some light on the development of this complication, they might in fact be only a secondary issue. As stated by the authors, "Stent grafting of the thoracic aorta ... has emerged as a promising alternative to surgical repair." In my opinion stent grafting should be viewed as an additional surgical strategy rather than an alternative one. In spite of its less-invasive nature, its success depends primarily on favorable anatomy, the most critical feature of which remains the length of the proximal landing zone. Absent an excellent landing zone $(>2 \mathrm{~cm}$ in length and without severe angulation, calcification, thrombus, or reverse taper), in a young healthy patient open surgical repair would appear the procedure of choice, especially in the elective situation. When we compromise those criteria necessary for a successful endovascular repair, treatment failures result. Perhaps these criteria might have existed. Certainly, hindsight offers a uniquely clear perspective. In my opinion, however, it is the older and sicker patient who most benefits from this stent graft technology or perhaps the acute trauma patient with contraindications to an open surgical procedure, usually involving heparinization and left heart bypass. For a young, healthy patient in a totally elective situation, an open surgical procedure, technically straightforward and with known long-term durability, would appear to offer overwhelming advantages. Until we have data on the long-term durability of stent grafts, for younger patients with suboptimal stent graft anatomy and without surgical contraindications, open surgical repair should remain the procedure of choice.

\section{Reference}

1. Bauernschmitt R, Voss B, Will A, Schirmbeck EU, Christian Firschke C, Martinoff S, et al. Stent-grafting of the descending aorta: value of early postinterventional computed tomographic control. J Thorac Cardiovasc Surg. 2006;132:e25-6. 